\title{
The role of upper level diffluence in the Tropical Easterly Jet in the formation of the recent strongest Atlantic hurricanes
}

\author{
T. N. Krishnamurti ${ }^{* 1}$, Nirupam Karmakar ${ }^{\dagger 1}$, Vasubandhu Misra ${ }^{1,2,3}$, Bappaditya Nag $^{1}$, \\ Dipak Sahu ${ }^{1}$, Sarvesh Dubey ${ }^{1}$, and Ziad Haddad ${ }^{4}$ \\ ${ }^{1}$ Department of Earth, Ocean and Atmospheric Science, Florida State University, Tallahassee, FL, USA. \\ ${ }^{2}$ Center for Ocean-Atmospheric Prediction Studies, Florida State University, Tallahassee, FL, USA. \\ ${ }^{3}$ Florida Climate Institute, Florida State University, Tallahassee, FL, USA. \\ ${ }^{4}$ Jet Propulsion Laboratory, California Institute of Technology, Pasadena, California, USA.
}

\begin{abstract}
In this paper we report the evidence of the potential role of diffluence in the $200 \mathrm{hPa}$ wind field off the coast of West Africa in the formation of a significant number of Category 4 and Category 5 hurricanes in the recent decade. It is shown that on an average of $65 \%$ cases of hurricanes at Category 4 and above is preceded by upper level diffluence in the Tropical Easterly Jet (TEJ) by 0-3 days. This TEJ is the outflow from the southern flank of the Tibetan anticyclone from the Asian monsoon region.
\end{abstract}

KEYWORDS Atlantic hurricanes; Upper level divergence; Diffluence

\footnotetext{
${ }^{*}$ Deceased

†Corresponding author; email: nirupam.ju@gmail.com; nkarmakar@fsu.edu
} 


\section{Introduction}

The Tropical Easterly Jet (TEJ) that originates in the heart of the monsoon (Arabian sea) and makes it way to the eastern Atlantic via all of North Africa (Figure 1) is one of the most well known features of the Asian monsoon circulation in the upper troposphere (Koteswaram 1958, Flohn 1964). The TEJ forms the outflow in the southern flank of the Tibetan anticyclone. Koteswaram (1958) explained that the TEJ was an outcome of the zonally symmetric meridional differential heating between the elevated heat source of the Tibetan plateau and the cooler Indian ocean. However, detailed energetics study of the TEJ following Kanamitsu et al. (1972) and Chen (1980) reveal that the TEJ is maintained by the tropical divergent circulations that includes both the Hadley and Walker circulations.

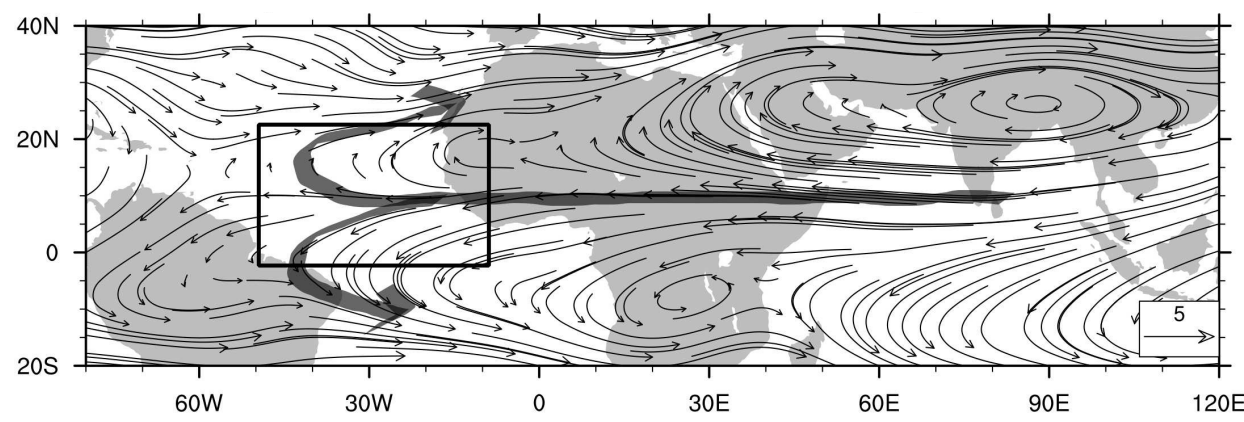

Figure 1: Average upper tropospheric winds during the formation of recent Category 5 hurricanes (19792014; 14 noted) over the Atlantic basin showing the diffluence over the eastern Atlantic Ocean. Unit of wind is $m / s$.

The purpose of this study is to document the potential relationship of favorable conditions in the upper troposphere just off the coast of West Africa for cyclogenesis of Category 4 and Category 5 Atlantic hurricanes as a result of the variations in the TEJ. It is quite interesting to note that a significant fraction of Category 5 hurricanes in the Atlantic have their cyclogenesis in the eastern Atlantic, approximately in the region where TEJ is exiting the African coast (Figure 2). As noted earlier in Figure 1, this region of eastern Atlantic is where the TEJ approximately splits with a southern branch recurving in to westerlies south of the equator and a northern branch recurving and merging with the westerlies of the mid-latitudes. 


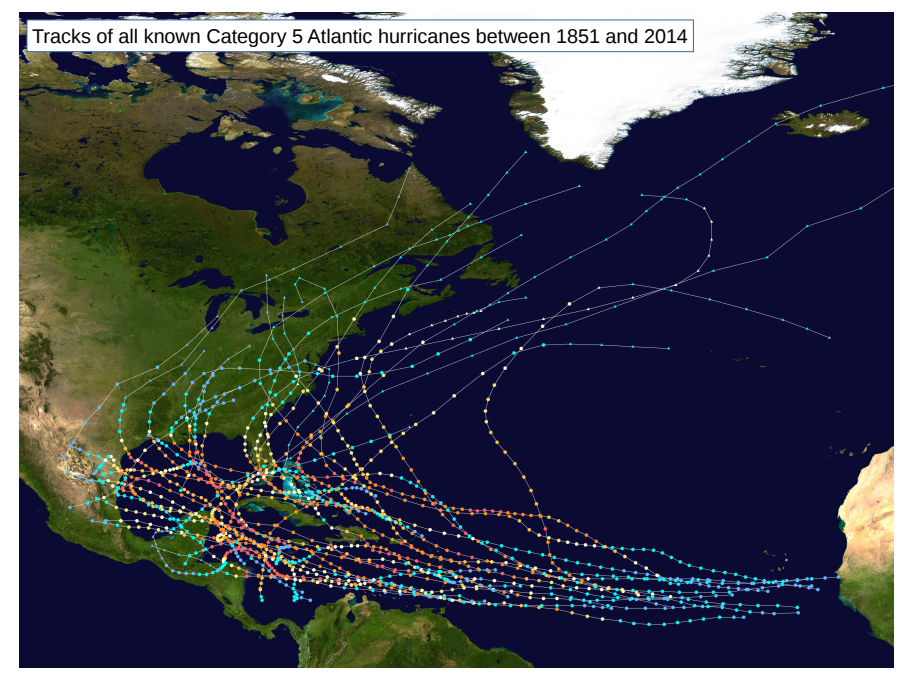

Figure 2: Tracks of all known Category 5 hurricanes between 1851-2014 (Source: Wikipedia).

\section{Datasets}

Winds at various vertical levels from ECMWF ReAnalysis (ERA)-Interim (Dee et al. 2011) and the NOAA (National Oceanic \& Atmospheric Administration) OISST (Optimum Interpolation Sea Surface Temperature) version 2 daily data (Reynolds et al. 2007) are used here. Temporal resolution of the data is 6-hourly and horizontal resolution is $0.75^{\circ} \times 0.75^{\circ}$.

We also use National Oceanic \& Atmospheric Administration (NOAA) Optimum Interpolation Sea Surface Temperature (OISST) version 2 daily data (Reynolds et al. 2007). Tracks of the hurricanes for the last 11 years (2007-2017) is obtained from National Hurricane Center (http: / /www . nhc . noaa. gov/data/).

\section{What is diffluence}

Diffluence is a kinematic feature of the horizontal motion field. Balance of forces can be better understood if a horizontal coordinate system is chosen which is naturally aligned with the flow, instead of 
Cartesian or spherical coordinates. Diffluence arises from the translation of the familiar horizontal divergence in Cartesian coordinates $(x, y)$ into natural coordinates $(s, n)$. In natural coordinates, one direction is chosen aligned with the streamline $(s)$, parallel with the flow, and another direction is always normal to its left $(n)$. Figure 3 represents the $(x, y)$ and $(s, n)$ coordinates. Unit vectors $(\mathbf{s}, \mathbf{n})$ represent a right-handed curvilinear coordinate system. Horizontal velocity is defined as $\mathbf{V}=V \mathbf{s}$. Angle $\alpha$ denotes the angle of the flow with respect to the west-east direction, with positive values indicate counter-clockwise rotation.

Horizontal gradient operator in $(s, n)$ system is defined as

$$
\nabla=\mathbf{s} \frac{\partial}{\partial s}+\mathbf{n} \frac{\partial}{\partial n}
$$

Simple calculations lead to the derivation of horizontal divergence in natural coordinate system from Cartesian coordinates:

$$
\nabla \bullet \mathbf{V}=\frac{\partial u}{\partial x}+\frac{\partial v}{\partial y}(\text { Cartesian })=\frac{\partial V}{\partial s}+V \frac{\partial \alpha}{\partial n}(\text { Natural })
$$

The first term of the natural coordinate system denotes speed divergence or along-flow speed variations and the second term denotes diffluence. Diffluence arises from changes of the flow angle with respect to the normal to the direction $\mathbf{n}$. The computations of these two terms of the natural coordinates were facilitated by the transformation functions provided by Bell \& Keyser (1993). The transformation relation for the first term is:

$$
\frac{\partial V}{\partial s}=\frac{1}{V^{2}}\left[\left(u^{2} u_{x}+v^{2} v_{y}\right)+u v\left(v_{x}+u_{y}\right)\right]
$$

where, $V$ is the total wind speed, and $u, v$ are the local west to east and south to north wind components. The subscripts denote respective derivatives with respect to $x$ and $y$.

Diffluence $\left(V \frac{\partial \alpha}{\partial n}\right)$ can be found out by subtracting the speed divergence in Equation 3 from the 


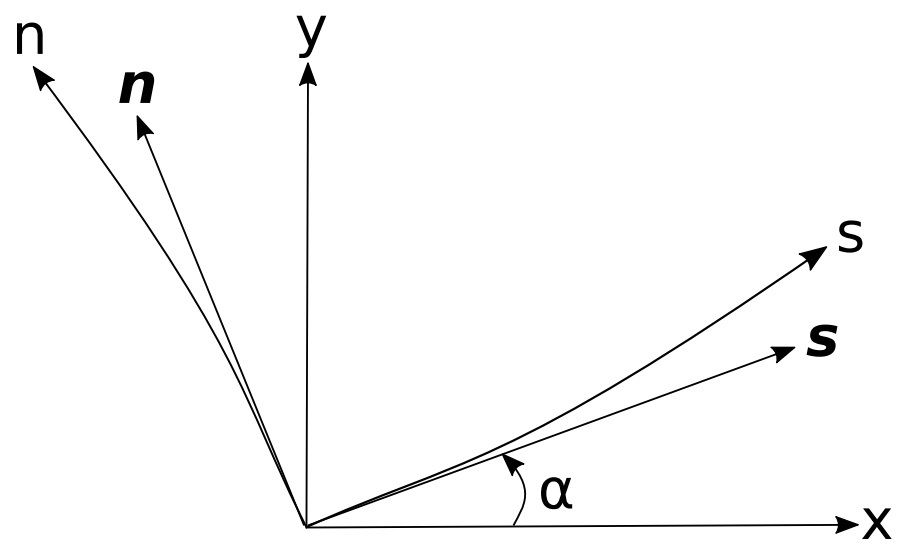

Figure 3: Schematic illustration of natural coordinate system $(s, n)$ used to define diffluence in this study. $s$ is always parallel to the flow and $n$ is orthogonal it. This coordinate system is defined locally. The unit vectors, $\mathbf{s}(=\mathbf{V} / V)$ and $\mathbf{n}(=\mathbf{k} \times \mathbf{s})$ are also shown. Angle between the direction of motion (s) and west-east direction ( $x$-axis) is $\alpha$. (Following Bell \& Keyser (1993))

total divergence easily obtained from the Cartesian coordinates system. Therefore,

$$
V \frac{\partial \alpha}{\partial n}=\nabla \bullet \mathbf{V}-\frac{\partial V}{\partial s}, \quad \text { where } \quad \alpha=\cos ^{-1}\left(\frac{u}{v}\right)
$$

These are easy to use and fields of speed divergence and diffluence can be mapped. The Tropical Easterly Jet (TEJ) at the $200 \mathrm{hPa}$ level weakens abruptly as it exits west coast of Africa and shows a speed convergence (Figure 4). Whereas, the diffluence of the TEJ is positive and larger in magnitude. This implies that the directional divergence exceeds the speed convergence, thus, in general there is a net divergence over the eastern Atlantic Ocean. In subsequent discussions, we shall show more precise values of these two terms in the context of several intense hurricane formation periods.

\section{Results}

The July-September average fields during 2017 shown in Figure 4 reveals some interesting features of the upper tropospheric flow in the tropics. Speed convergence is seen over most of the African region and parts 
of eastern Atlantic along $15^{\circ} \mathrm{N}-20^{\circ} \mathrm{N}$, associated with the TEJ. Positive diffluence is seen over the same regions with the winds associated with the TEJ bifurcating over the tropical eastern Atlantic. The stretch of this strong positive diffluent pattern is from central India to the middle of the Atlantic, showing the vastness of monsoonal flow in the upper troposphere. Existence of the Tibetan high along with the strong anticyclonic flow over northern India is seen. The extent and strength of the diffluent patterns over the eastern Atlantic is possibly linked with the structure of the Tibetan high.

(a) Speed divergence
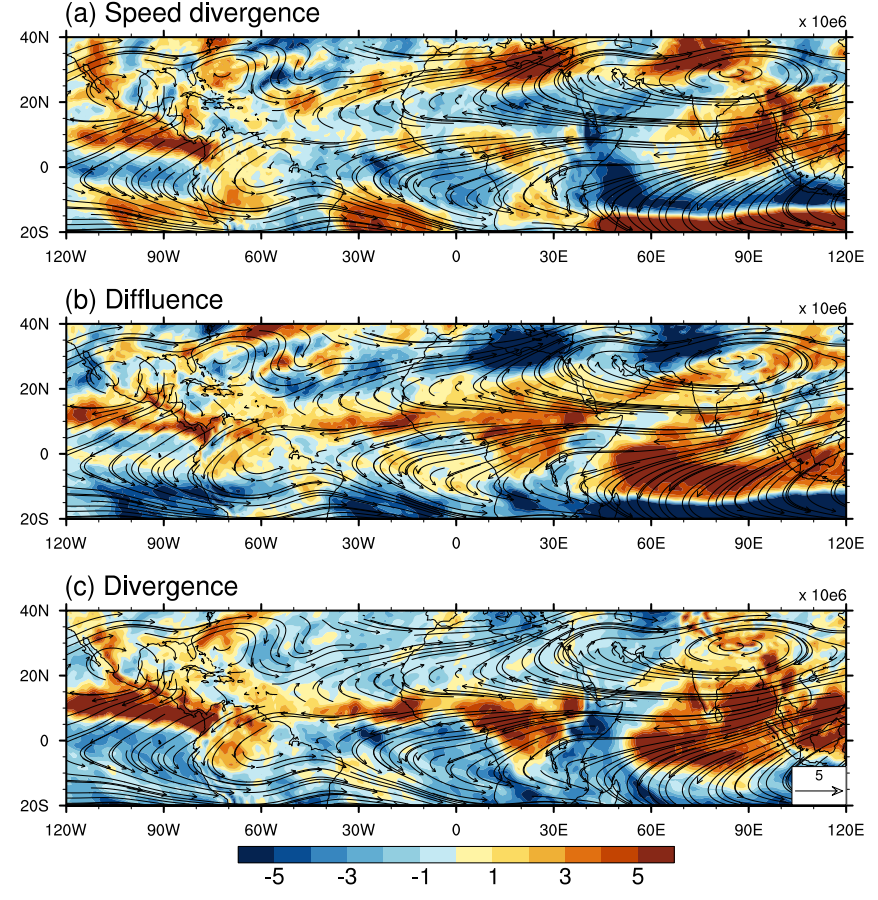

Figure 4: (a) July-September averaged speed divergence as calculated using the equations described in the text for 2017 overlayed with 200-hPa wind vectors. (b) Same as (a) but for diffluence (c) Same as (a) but for divergence. Unit of wind is $\mathrm{m} / \mathrm{s}$. Speed divergence, diffluence and divergence are scaled by $10^{6}$ and have units $s^{-1}$.

The primary aim of this study is to investigate whether this diffluent patterns over the eastern Atlantic play a role in generating some of the strongest hurricanes in recent time. Table 1 lists the category 4 and 5 hurricanes formed over the Atlantic in the most recent 11 years (2006-2017). Most of these hurricanes (13 out of 20) formed between 1 August-15 September. TEJ is strongest during this period and weakens after mid-September. Paloma occurred in November and is excluded from any of the analysis in this study. 
Table 1: Category 4 and 5 hurricanes during 2007-2017.

\begin{tabular}{|c|c|c|c|c|c|}
\hline Name (year) & Category & $\begin{array}{c}\text { Date left } \\
\text { African coast }\end{array}$ & $\begin{array}{c}\text { Date } \\
\text { named }\end{array}$ & $\begin{array}{c}\text { Location } \\
\text { where named }\end{array}$ & Date of death \\
\hline Dean (2007) & 5 & $08 / 11$ & $08 / 13$ & $\left(12^{\circ} \mathrm{N}, 29^{\circ} \mathrm{W}\right)$ & $08 / 23$ \\
\hline Felix (2007) & 5 & $08 / 24$ & $08 / 31$ & $\left(13^{\circ} \mathrm{N}, 57^{\circ} \mathrm{W}\right)$ & $09 / 06$ \\
\hline Gustav (2008) & 4 & $08 / 13$ & $08 / 31$ & $\left(14^{\circ} \mathrm{N}, 67^{\circ} \mathrm{W}\right)$ & $09 / 05$ \\
\hline Ike (2008) & 4 & $08 / 28$ & $09 / 01$ & $\left(17^{\circ} \mathrm{N}, 37^{\circ} \mathrm{W}\right)$ & $09 / 15$ \\
\hline Omar (2008) & 4 & $09 / 30$ & $10 / 13$ & $\left(15^{\circ} \mathrm{N}, 69^{\circ} \mathrm{W}\right)$ & $10 / 21$ \\
\hline Paloma (2008) & 4 & $11 / 01$ & $11 / 05$ & $\left(14^{\circ} \mathrm{N}, 82^{\circ} \mathrm{W}\right)$ & $11 / 14$ \\
\hline Bill (2009) & 4 & $08 / 12$ & $08 / 15$ & $\left(12^{\circ} \mathrm{N}, 32^{\circ} \mathrm{W}\right)$ & $08 / 26$ \\
\hline Danielle (2010) & 4 & $08 / 18$ & $08 / 21$ & $\left(11^{\circ} \mathrm{N}, 31^{\circ} \mathrm{W}\right)$ & $09 / 03$ \\
\hline Earl (2010) & 4 & $08 / 23$ & $08 / 24$ & $\left(13^{\circ} \mathrm{N}, 19^{\circ} \mathrm{W}\right)$ & $09 / 06$ \\
\hline Igor (2010) & 4 & $09 / 06$ & $09 / 08$ & $\left(14^{\circ} \mathrm{N}, 23^{\circ} \mathrm{W}\right)$ & $09 / 23$ \\
\hline Julia (2010) & 4 & $09 / 11$ & $09 / 12$ & $\left(13^{\circ} \mathrm{N}, 21^{\circ} \mathrm{W}\right)$ & $09 / 24$ \\
\hline Katia (2011) & 4 & $08 / 27$ & $08 / 28$ & $\left(10^{\circ} \mathrm{N}, 19^{\circ} \mathrm{W}\right)$ & $09 / 12$ \\
\hline Ophelia (2011) & 4 & $09 / 16$ & $09 / 20$ & $\left(12^{\circ} \mathrm{N}, 37^{\circ} \mathrm{W}\right)$ & $10 / 04$ \\
\hline Gonzalo (2014) & 4 & $10 / 04$ & $10 / 11$ & $\left(16^{\circ} \mathrm{N}, 55^{\circ} \mathrm{W}\right)$ & $10 / 20$ \\
\hline Joaquin (2015) & 4 & $09 / 19$ & $09 / 26$ & $\left(27^{\circ} \mathrm{N}, 69^{\circ} \mathrm{W}\right)$ & $10 / 15$ \\
\hline Matthew (2016) & 5 & $09 / 23$ & $09 / 28$ & $\left(13^{\circ} \mathrm{N}, 60^{\circ} \mathrm{W}\right)$ & $10 / 10$ \\
\hline Nicole (2016) & 4 & $09 / 25$ & $10 / 04$ & $\left(23^{\circ} \mathrm{N}, 60^{\circ} \mathrm{W}\right)$ & $10 / 19$ \\
\hline Harvey (2017) & 4 & $08 / 11$ & $08 / 17$ & $\left(13^{\circ} \mathrm{N}, 55^{\circ} \mathrm{W}\right)$ & $09 / 01$ \\
\hline Irma (2017) & 5 & $08 / 27$ & $08 / 30$ & $\left(16^{\circ} \mathrm{N}, 30^{\circ} \mathrm{W}\right)$ & $09 / 12$ \\
\hline Jose (2017) & 4 & $09 / 02$ & $09 / 05$ & $\left(12^{\circ} \mathrm{N}, 39^{\circ} \mathrm{W}\right)$ & $09 / 24$ \\
\hline Maria (2017) & 5 & $09 / 11$ & $09 / 16$ & $\left(12^{\circ} \mathrm{N}, 53^{\circ} \mathrm{W}\right)$ & $09 / 24$ \\
\hline
\end{tabular}

Tracks of these 20 hurricanes and upper-level wind fields on days before the hurricanes were named were also investigated. Almost all the hurricanes which formed over the eastern Atlantic are associated with a bifurcation of TEJ (not shown). This leads us to investigate the structure of diffluence over that region before the storm formed and intensified.

Figure 5 shows the case for hurricane Irma in 2017. Irma was named on August 30, 2017. Spatial patterns of daily-averaged diffluence and upper level winds are plotted for 5 consecutive days from August 27. A strong positive diffluence is seen over the eastern Atlantic and western African coast on August 27. In subsequent days, this patch of positive diffluence moves westward and by August 30 a large area of remains positive around the location where Irma was named $\left(16^{\circ} \mathrm{N}, 30^{\circ} \mathrm{W}\right)$. The wind vectors also show propagation in their bifurcating nature over the region along with the diffluence.

\footnotetext{
${ }^{1}$ Paloma is not considered for any calculation.
} 


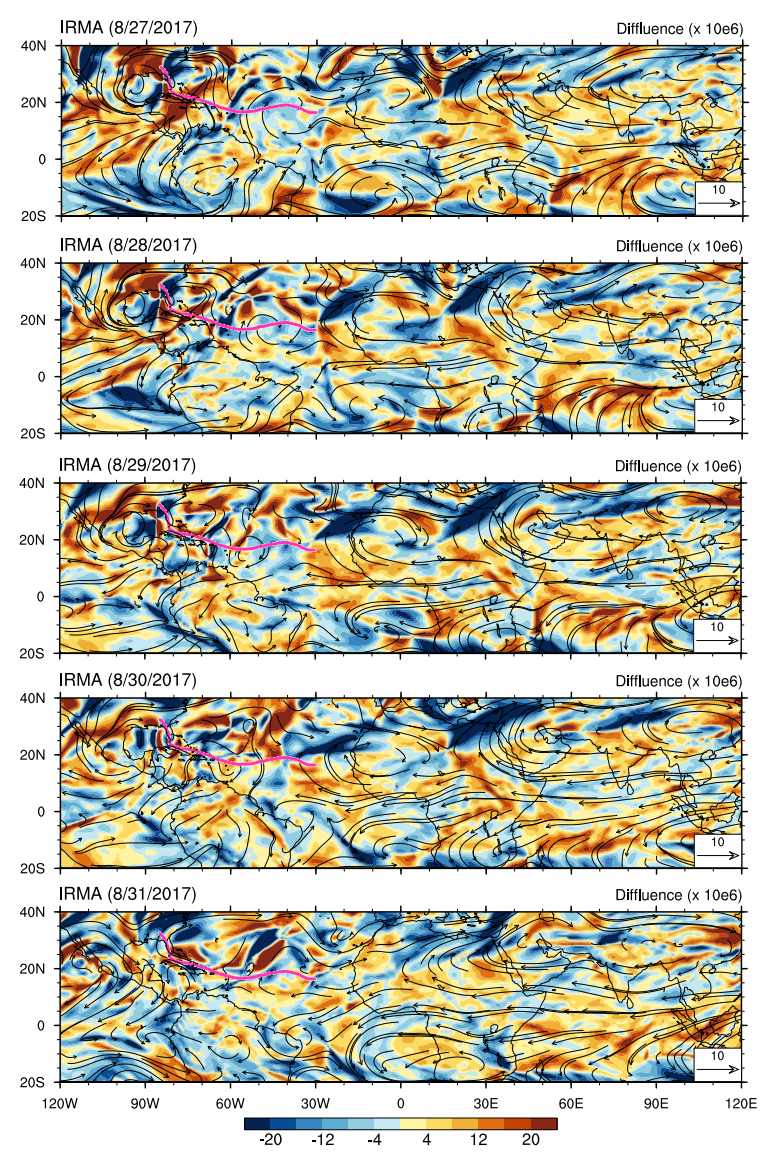

Figure 5: Diffluence at 200hPa is plotted during 27-31 August, 2017, when hurricane Irma formed. Irma was named on $30^{\text {th }}$ August. Wind vectors at $200 \mathrm{hPa}$ are also shown. Pink line indicates the track of Irma after it was named. Units of wind and diffluence are $\mathrm{m} / \mathrm{s}$ and $\times 10^{6} \mathrm{~s}^{-1}$, respectively.

In Figure 6a meridional component of winds at lower troposphere $(850 \mathrm{hPa})$ is shown in a hovmoller diagram. African easterly waves (AEW) are most prominent in the lower troposphere (mostly 850$700 \mathrm{hPa}$ level). Alternating signs within this 10-day period of the hovmoller diagram shows the high frequency of the easterly waves emanating from the African coast. Typically, within every 2-6 days AEW emanates from the coast of Africa during this time of the year (Burpee 1974, Thorncroft \& Hodges 2001, Kiladis et al. 2006). Irma is marked by a strong wave signal originating from almost the central African region and escalating afterwards. Positive values of diffluence, as shown in Figure 4b, also shows propagation before Irma formed and later named. 

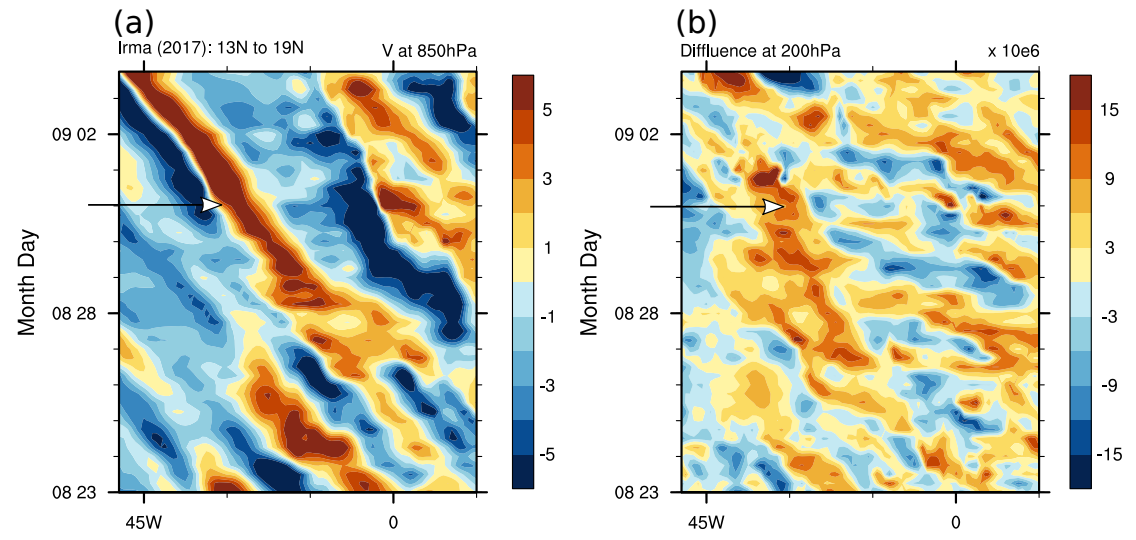

Figure 6: Hovmoller diagrams of (a) Meridional wind and (b) Diffluence at 200hPa plotted during August 23 - September 3, 2017, when hurricane Irma formed. Latitudinal averaging between $13^{\circ} \mathrm{N}-19^{\circ} \mathrm{N}$ is shown. Units of wind and diffluence are $m / s$ and $\times 10^{6} s^{-1}$, respectively. Arrows mark the date and longitude when Irma was named.

This raises an important question: As AEW emanate in every 2-6-days, not all AEW turn into major hurricanes. Therefore, what are the important factors that critically modulates the growth of these waves and transform them into intense storms? The analysis presented till now hints towards the fact that the upper level diffluence is strongly associated with the formation of Irma. We also found similar patterns of diffluence for other hurricanes (not shown).

Further investigation on how diffluence plays a major role in formation of Irma is done by calculating upper level diffluence averaged over a horizontal region to the west of the African coast $\left(8^{\circ} \mathrm{N}-15^{\circ} \mathrm{N}\right.$, $15^{\circ} \mathrm{W}-45^{\circ} \mathrm{W}$ ) during the passage of the AEW associated with Irma (Figure 7). Latitudinally, this box centers the location where AEW typically exits the African land (Pytharoulis \& Thorncroft 1999, Thorncroft \& Hodges 2001, Kiladis et al. 2006). Figure 7a shows the evolution of SST over the African coast. Although SST in this region remains above $27^{\circ} \mathrm{C}$ during boreal summer, it went up to nearly $28.6^{\circ} \mathrm{C}$ when Irma formed, favoring enhanced evaporation and higher moisture supply. Figures $7 \mathrm{~b}, \mathrm{c}$ and $\mathrm{d}$ represents upper level divergence, lower level vorticity and upper level diffluence over the region, respectively. Low-level vorticity shows a maxima on August 28, indicating the presence of a strong cyclonic flow. Divergence shows the maxima on August 23 over that region and almost all of the divergence is contributed by the diffluence. This shows how diffluence over the African coast builds up and peaks well before the hurricane is formed. 
This increase in the diffluence essentially favors the convective outflow in the upper troposphere and hence, enhances the low level convergence through Dines compensation. Basically, this upper level diffluence is balanced by the mid-tropospheric vertical motion and lower level convergence. The presence of higher SST, low level vorticity and upper level diffluence together support the development of one of the most intense hurricane in the Atlantic.
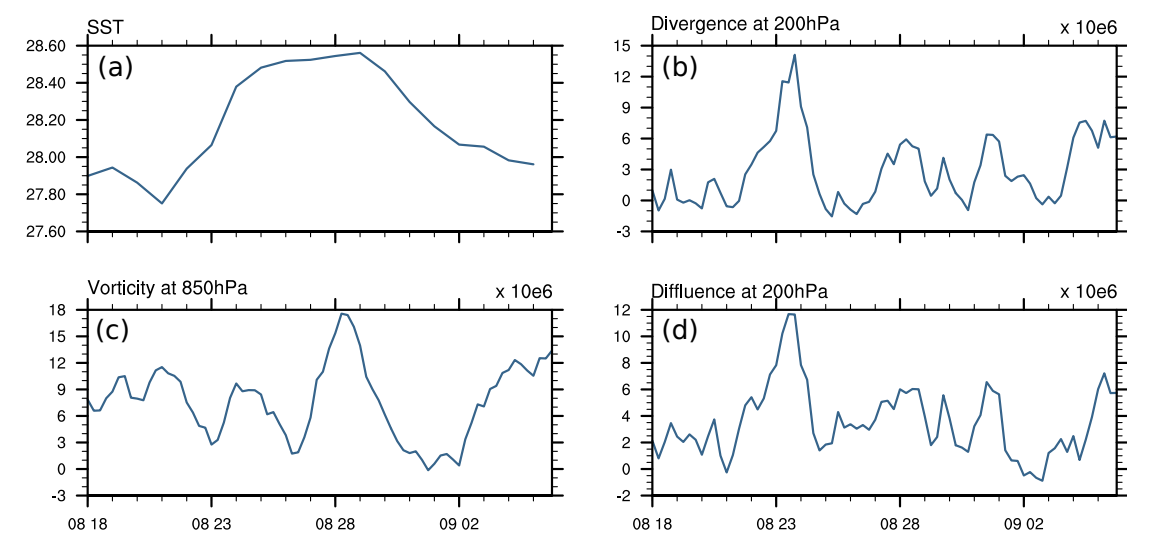

Figure 7: Area-averaged values for (a) Sea surface temperature, (b) Divergence at $200 \mathrm{hPa}$, (c) Vorticity at $850 \mathrm{hPa}$, and (d) Diffluence at 200hPa plotted during August 18- September 5, 2017, when hurricane Irma formed. Horizontal box where averaging is done is $\left(8^{\circ} \mathrm{N}-15^{\circ} \mathrm{N}, 15^{\circ} \mathrm{W}-45^{\circ} \mathrm{W}\right)$. Units of vorticity and diffluence are $\times 10^{6} s^{-1}$, and SST is in ${ }^{\circ} \mathrm{C}$. Irma was named on August 30, 2017.

Evolution of upper level diffluence is tested for all the 20 hurricanes listed in Table 1. Compositing all the storms based on their naming date could be one way of observing the mean picture. However, this method can actually lead to misinterpretation of diffluence and vorticity association. Primarily, because of the variability of speed in the propagation of diffluence patterns and low-level vorticity. Furthermore, the translation speed varies for different tropical cyclones. Another reason is two hurricanes can occur very close temporally, which would make it difficult to separate out the peaks in diffluence for two different hurricanes and associate them with the development of low level vorticity. Therefore, compositing based on a fixed date (naming date or the date when the vorticity maxima left Africa) can be misleading or might average out the signal.

Therefore, we investigate each storm separately and find out the local peak in upper level diffluence before the local maxima in low level vorticity related to the storm (Table 2). Now, these values are calculated 
Table 2: Averaged diffluence and speed divergence for the 20 hurricanes. See text for how averaging is done. Units are $\times 10^{6} s^{-1}$ for each quantity.

\begin{tabular}{|c|c|c|c|c|c|}
\hline Name (year) & $\begin{array}{c}\text { Vorticity peak } \\
\text { value (mm-dd:hr) }\end{array}$ & $\begin{array}{c}\text { Diffluence peak } \\
\text { value (mm-dd:hr) }\end{array}$ & Divergence & $\begin{array}{c}\text { Speed } \\
\text { divergence }\end{array}$ & $\begin{array}{c}\text { Lead } \\
\text { (hours) }\end{array}$ \\
\hline Dean (2007) & $16.0(08-11: 06)$ & $8.5(08-11: 06)$ & 8.0 & -0.5 & 00 \\
\hline Felix (2007) & $11.0(08-30: 06)$ & $5.3(08-27: 18)$ & 3.9 & -1.4 & 60 \\
\hline Gustav (2008) & $4.0(08-29: 12)$ & $4.6(08-24: 06)$ & 1.9 & -2.7 & 126 \\
\hline Ike (2008) & $13.5(08-31: 06)$ & $6.0(08-27: 18)$ & 3.3 & -2.7 & 84 \\
\hline Omar (2008) & $8.5(10-13: 18)$ & $3.0(10-11: 00)$ & 3.2 & 0.2 & 66 \\
\hline Bill (2009) & $13.2(08-15: 06)$ & $8.6(08-10: 18)$ & 9.2 & 0.6 & 108 \\
\hline Danielle (2010) & $14.4(08-19: 12)$ & $8.7(08-18: 00)$ & 10.6 & 1.9 & 36 \\
\hline Earl (2010) & $6.5(08-23: 06)$ & $6.0(08-21: 00)$ & 4.0 & -2.0 & 54 \\
\hline Igor (2010) & $13.2(09-07: 18)$ & $5.0(09-07: 18)$ & 6.6 & 1.6 & 00 \\
\hline Julia (2010) & $11.9(09-12: 06)$ & $6.5(09-11: 18)$ & 3.5 & -3.0 & 12 \\
\hline Katia (2011) & $11.6(08-28: 06)$ & $7.1(08-26: 12)$ & 10.9 & 3.8 & 42 \\
\hline Ophelia (2011) & $16.0(09-19: 12)$ & $5.1(09-18: 06)$ & 7.5 & 2.6 & 30 \\
\hline Gonzalo (2014) & $3.9(10-10: 06)$ & $0.5(10-06: 06)$ & 4.2 & 3.7 & 96 \\
\hline Joaquin (2015) & $6.9(09-27: 18)$ & $1.4(09-22: 18)$ & 1.4 & 0.0 & 114 \\
\hline Matthew (2016) & $8.7(09-28: 00)$ & $7.0(09-27: 00)$ & 6.2 & -0.8 & 24 \\
\hline Nicole (2016) & $-1.2(09-29: 18)$ & $-1.5(10-01: 00)$ & -2.7 & -1.2 & -30 \\
\hline Harvey (2017) & $13.5(08-14: 18)$ & $9.3(08-14: 00)$ & 9.2 & 0.1 & 18 \\
\hline Irma (2017) & $12.6(08-28: 00)$ & $9.5(08-23: 18)$ & 15.0 & 5.5 & 54 \\
\hline Jose (2017) & $13.1(09-04: 06)$ & $5.2(08-31: 12)$ & 6.4 & 1.2 & 90 \\
\hline Maria (2017) & $10.1(09-15: 18)$ & $9.8(09-15: 18)$ & 12.9 & 3.1 & 00 \\
\hline
\end{tabular}

by averaging over a horizontal box to the east of where each storm is first named. The size of the box is taken as $9^{\circ}$ (latitudinally) $\times 30^{\circ}$ (longitudinally), with the location where the storm is named is located on the center of the leftmost line of the box. So, the location of the box varies for each storm while keeping the size of the box constant. This enables us to see the evolution of upper level diffluence during the intensification of the storms.

Table 2 provides the values of temporally local maxima in low level vorticity, upper level diffluence and the time the peak in diffluence leads the vorticity maxima for each storm. It is observed that maxima in diffluence occurs almost $0-5$ days prior to the peak in low level vorticity (except for Nicole). This table clearly points to a potential role of the upper level diffluence facilitating the further maturation of the low level vorticity to a major hurricane category. 


\section{Summary and Discussions}

This work documents the close relationship of the occurrence of diffluence in the TEJ when it is exiting the west African coast preceding the cyclogenesis of the potential Category 4 and Category 5 Atlantic hurricanes. It is shown that of the 21 Category 4 and Category 5 hurricanes in the Atlantic between 20072017, 19 of them were preceded by significant diffluence in TEJ exiting the west African coast. 13 of them shows a peak in diffluence 3 days before the hurricane formed. A detailed examination for the case study of hurricane Irma of 2017 indicate that the peak in low level vorticity over eastern Atlantic was preceded by a maximum in diffluence at $200 \mathrm{hPa}$.

We posit that under favorable conditions of warm SST, abundant mid-level moisture, the precursor of upper level diffluence provided sufficient positive forcing for the incipient low level vorticity to mature to Category 5 hurricane in the case of Irma.

\section{Acknowledgement}

This is one of the last ideas of Prof. T. N. Krishnamurti that he was actively working on before he passed away on February 7, 2018. This work is currently being worked by a number of his students and will be put out to a peer reviewed journal in a short order. This work is supported by NASA grants NNX17AGS001 and NNX16AD83GS003.

\section{References}

Bell, G. D. \& Keyser, D. (1993). Shear and curvature vorticity and potential-vorticity interchanges: Interpretation and application to a cutoff cyclone event, Mon. Wea. Rev. 121(1): 76-102.

Burpee, R. W. (1974). Characteristics of North African easterly waves during the summers of 1968 and 1969, J. Atmos. Sci. 31(6): 1556-1570.

Chen, T.-C. (1980). On the energy exchange between the divergent and rotational components of atmo- 
spheric flow over the tropics and subtropics at $200 \mathrm{mb}$ during two northern summers, Mon. Wea. Rev. 108(7): 896-912.

Dee, D., Uppala, S., Simmons, A., Berrisford, P., Poli, P., Kobayashi, S., Andrae, U., Balmaseda, M., Balsamo, G., Bauer, P. et al. (2011). The ERA-Interim reanalysis: Configuration and performance of the data assimilation system, Quart. J. Roy. Meteor. Soc. 137(656): 553-597.

Flohn, H. (1964). Investigations on the tropical easterly jet, Vol. 4, Bonner Meteorol. Abh., pp. 1-83.

Kanamitsu, M., Krishnamurti, T. \& Depradine, C. (1972). On scale interactions in the tropics during northern summer, J. Atmos. Sci. 29(4): 698-706.

Kiladis, G. N., Thorncroft, C. D. \& Hall, N. M. (2006). Three-dimensional structure and dynamics of African easterly waves. Part I: Observations, J. Atmos. Sci. 63(9): 2212-2230.

Koteswaram, P. (1958). The easterly jet stream in the tropics, Tellus 10(1): 43-57.

Pytharoulis, I. \& Thorncroft, C. (1999). The low-level structure of African easterly waves in 1995, Mon. Wea. Rev. 127(10): 2266-2280.

Reynolds, R. W., Smith, T. M., Liu, C., Chelton, D. B., Casey, K. S. \& Schlax, M. G. (2007). Daily highresolution-blended analyses for sea surface temperature, J. Clim. 20(22): 5473-5496.

Thorncroft, C. \& Hodges, K. (2001). African easterly wave variability and its relationship to Atlantic tropical cyclone activity, J. Climate 14(6): 1166-1179. 